\title{
A SIMPLIFIED BUT EFFECTIVE METHOD FOR THE QUALITY CONTROL OF MEDICINAL PLANTS BY PLANAR CHROMATOGRAPHY
}

\section{JN Eloff*, DT Ntloedibe and R van Brummelen}

\author{
Phytomedicine Programme, Dept of Paraclinical Sciences, Faculty of Veterinary Science, University \\ of Pretoria, Private Bag X04, Onderstepoort, 0110 South Africa \\ E-mail: kobus.eloff@up.ac.za
}

\begin{abstract}
Three of the factors limiting the rational use of herbal medicine are uncertainty on effectivity, uncertainty on safety and variation in quality of the product. Because many herbal medicines have been used over centuries by indigenous peoples, the safety and effectivity is frequently not such a big concern. With more people collecting and distributing herbal medicine, the offered product is however, frequently not what the label indicates either through a genuine mistake, but also through fraud especially where expensive herbal medicine is concerned. Some wrong identifications have already led to serious side effects and deaths. Planar chromatography or thin layer chromatography [TLC] is widely used to verify the identity of plant extracts by determining the chemical fingerprint of the extracts. In a leading publication 17 different extractants, 41 solvent systems and 44 spray reagents have been used to verify the identity of important herbal preparations. We investigated whether a simplified system could not be developed to aid small laboratories in identifying different herbal medicines. We compared the efficacy of different extractants, identified and developed three TLC solvent systems that would separate compounds with low, medium and high polarity and then also investigated the use of several spray reagents. With acetone as extractant and benzene:ethanol:ammonia [9:1:0.1], chloroform:ethylacetate:formic acid [5:4:1] and ethylacetate:methanol:water [10:1.35:1] as TLC solvent system and vanillin-sulphuric acid as spray reagent the identity of 81 samples of more than 50 herbal preparations could be verified on the basis of the chromatograms. The same product from different suppliers usually gave similar chromatograms. More importantly in several cases it was clear that products with the same label were so different that a mistake must have occurred in the labelling. This method has found application in the quality control of the most important African medicinal plants in the recently published African Herbal Pharmacopoeia produced by the Association for African Medicinal Plant Standards (AAMPS).
\end{abstract}

\section{Introduction}

There has been a substantial growth in the use of herbal medicines in parts of the world where it was not used extensively in the past. There are many reasons why people use herbal medicines. According to a survey in the USA people use herbal medicines because they prefer natural products [47\%], there are fewer side effects [17\%], it is more efficient [17\%], it is less expensive [10\%] and it is milder [8\%]. At least in his group of consumers price was not a major factor (McCaleb, 2000).

Robbers and Tyler [1999] distinguish between paraherbalism, which is based on pseudoscience, and rational herbalism where herbal medicine is used based on scientifically verifiable evidence. In paraherbalism, which includes homeopathy as "a particularly pernicious form of paraherbalism", the effects achieved could be due to a placebo effect or are at least not reproducible and scientifically verifiable at this stage. On the other hand rational herbalism is based on plants containing relatively low concentrations of pharmacologically active compounds that can be evaluated in clinical trials. Herbal medicines as are therefore in effect dilute drugs.

The main factors that limit the rational use of herbal medicine on the same level as pharmaceutical products are [a] the efficacy of the herbal medicine has to be proven, [b] the safety of the herbal medicine has to be proven and [c] the quality control of herbal medicines have to be improved.

The strong growth of the herbal medicine market for long periods may be an indication of efficacy of herbal medicine even though clinical trials may not have taken place. Due to the difficulty of patenting herbal medicines, funding restricts adequate clinical trials to prove efficacy. Some registering authorities are more concerned with safety than with efficacy and accept that because traditional healers have used plants to treat people in fact informal clinical trials have been taking place over many years. It is frequently accepted that traditional healers have collected their information over hundreds even thousands of years. In many cases however, relatively recently introduced invasive or domesticated species are used. Furthermore the many claims for being able to treat a new disease such as AIDS shows that "informal clinical trials" are constantly undertaken regardless of any possible legal or ethical problems.

As far as safety is concerned, herbal medicine has been used for centuries by rural people and for decades by urban people and is frequently considered to be safe. For many herbal medicines approved in the German Commission E Monographs [Blumenthal et al., 1998] as prescription medicines, no clinical trials or long term toxicity studies have been carried out. Care should be however taken when a different extractant is used because the extractant has a major effect on the compounds extracted and biological activity of a plant extract (Kotze and Eloff, 2002).

Quality control is therefore one of the major problems in the rational use of herbal medicines. With many herbal medicines the active component is not known and genetic and environmental factors may influence the concentration of plant secondary compounds. Frequently a marker compound is selected and this is used to determine the quality of the herbal medicine.

In a study in North America no samples of feverfew (Tanacetum parthenium) examined contained the $0.2 \%$ parthenolide required for activity [Groenewegen and Heptinstall, 1986]. With more people collecting and distributing medicinal plants, the wrong plant is frequently offered either as a genuine mistake or in an effort to increase profits. In one study of 54 ginseng products, $60 \%$ were worthless and $25 \%$ contained no ginseng at all [Liberty and der Marderosian, 1978]. One of the important components of quality control is therefore 
to validate the identity of the plant in the product. High performance liquid chromatography is valuable to quantify chemical compounds in plant extracts, but planar chromatography also know as thin layer chromatography [TLC] has many advantages and is cheaper and easier to use than HPLC to identify plants by analyzing the chemical components of extracts. Wagner and Bladt (1996) did pioneering work in providing a TLC atlas of many herbal medicines with colour photographs of the chromatograms of plant extracts. They collated the methods developed by different scientists over many years. The methods compiled by Wagner and Bladt [1996] lists 17 different extractants 41 different TLC solvent systems, including several types of TLC plates and 44 different detecting spray reagents. Many of these procedures were targeted towards isolation and separation of the active compound in the specific medicinal plant. Some TLC methods specified in publications such as the British Herbal Pharmacopoeia do not include plates of the chromatograms and only provides an $R_{f}$ value.

Earlier results within the Phytomedicine Programme have shown that acetone is probably one of the best solvents to extract compounds of a wide range of polarity from dried plant material [Eloff, 1998]. In this study we compared acetone extraction with methanol under reflux extraction with a few selected medicinal plants. We developed additional TLC solvent systems to separate compounds with a large variation in polarity and also investigated different spray reagents for the TLC chromatograms. Finally we extracted and separated 83 commercially used herbal medicines representing close to 60 different medicinal plants.

Although sub-Saharan Africa and the Indian Ocean islands contain about a quarter of the worlds plant species, only $7.6 \%$ of the commercialized medicinal plants are from Africa (van Wyk and Wink, 2004). The values for Asia are close to $40 \%$. The reason is probably because the indigenous knowledge on African medicinal plants has not been documented. The Association for African Medicinal Plant Standards (AAMPS) a non-profit organization based in Mauritius has been established to promote the use of African medicinal plants in Europe and the USA [www.aamps.org]. AAMPS has identified the 50 most important African medicinal plant species in consultation with many stakeholders and with funding from the European agency Commission for the Development of enterprise (CDE). Trading standards/monographs on these species have been completed and the first edition of an African Herbal Pharmacopoeia has been published with funding from several European Union Agencies. The information is available on the website (www.aamps.org). The techniques developed in this contribution have been used in the African Herbal Pharmacopoeia.

\section{Materials and methods Plant material used}

Samples of herbal medicines were sourced through Biomox Pharmaceuticals Pty (Ltd) (www.biomox.com) a company that manufactures more than 1000 herbal medicines for more than 85 companies in southern Africa. The species used and the origin is shown in Table 1.

Table 1 : Herbal medicine obtained from Biomox Pharmaceuticals (Pty) Ltd

\begin{tabular}{|c|c|c|c|c|}
\hline Number & Common name & Scientific name & $\begin{array}{l}\text { Abbreviation } \\
\text { on TLC plate }\end{array}$ & Supplying compan \\
\hline 1 & Chaste tree fruit & Agnus casti & AG 1 & Bioharmony \\
\hline 2 & Chaste tree fruit & Agnus casti & $A G 2$ & * \\
\hline 3 & Chaste tree fruit & Agnus casti & $A G 3$ & * \\
\hline 4 & Marshmallow root & Althea roots & AT & * \\
\hline 5 & Lady's mantle & Alchemillae herb & $\mathrm{Al}$ & * \\
\hline 6 & Amara TB & Combined herbs & $\mathrm{AM}$ & Biomox \\
\hline 7 & Silverweed & Anserinae herba & AN 1 & Warrenchem \\
\hline 8 & Silverweed & Anserinae herba & AN 2 & Warrenchem \\
\hline 9 & Red cedar & Juniperus virginiana & $\mathrm{AP}$ & Warrenchem \\
\hline 10 & Biolite capsules & Combined herbs & $\mathrm{BI}$ & Biomox \\
\hline 11 & Bitter orange & Aurantii pericarpium & BT & Warrenchem \\
\hline 12 & Buckthorn & Rhamnus catharticus & BU 1 & Warrenchem \\
\hline 13 & Buckthorn & Rhamnus catharticus & $\mathrm{BU} 2$ & Bioharmony \\
\hline 14 & Cabbage skunk & Symplocarpus foetidus & $\mathrm{CA}$ & SAD \\
\hline 15 & Chamomile & Chamomile matricaria & $\mathrm{CH}$ & Warrenchem \\
\hline 16 & Cayenna powder & Capsici frutuscens $L$. & $\mathrm{CY}$ & * \\
\hline 17 & Chaste tree berry & Agnus castus & CS & Warrenchem \\
\hline 18 & Cinnamon & Cinnamomum verum & CN 1 & Bioharmony \\
\hline 19 & Cinnamon amara & Cinnamomum zeylanicum & $\mathrm{CN} 2$ & Bioharmony \\
\hline 20 & Cinnamon cortex & Cinnamomum verum & $\mathrm{CN} 3$ & Warrenchem \\
\hline 21 & Cloves powder & Syzygium sp & $\mathrm{CL}$ & Flora force \\
\hline 22 & Citrus extract & Citrus aurantium & CT & Warrenchem \\
\hline 23 & Dandelion root & Taraxacum officinale & DA & Warrenchem \\
\hline
\end{tabular}




\begin{tabular}{|c|c|c|c|c|}
\hline & & & & \\
\hline 24 & Echinaceae I & Echinaceae angustifolia & EC 1 & Bioharrmony \\
\hline 25 & Echinaceae & Echinaceae angustifolia & EC 2 & Warrenchem \\
\hline 26 & Emotone & Combined herbs & EM & Sportron \\
\hline 27 & Evening primrose & Oenothera biennis & EV & Warrenchem \\
\hline 28 & Bitter orange & Flores auranti & $\mathrm{FL}$ & Bioharmony \\
\hline 29 & Maidenhair tree & Ginkgo biloba & GB 1 & Warrenchem \\
\hline 30 & Maidenhair tree & Ginkgo biloba & GB 2 & Bioharmony \\
\hline 31 & Maidenhair tree & Ginkgo biloba & GB 3 & Biomox \\
\hline 32 & Maidenhair tree & Ginkgo biloba & GB 4 & Bioharmony \\
\hline 33 & Ginger root & Zingiber officinale & $\mathrm{GI}$ & Warrenchem \\
\hline 34 & Ginseng & Panax ginseng & GG 1 & Bioharmony \\
\hline 35 & Ginseng & Panax ginseng & GG 2 & Warrenchem \\
\hline 36 & Goldenseal & Hydratis canadensis & GS 1 & Bioharmony \\
\hline 37 & Goldenseal & Hydratis canadensis & GS 2 & Warrenchem \\
\hline 38 & Grapefruit seed & Vitus vinifera & GF & Warrenchem \\
\hline 39 & Grape skin extract & Vitus vinitera & GP & Bioharmony \\
\hline 40 & Guarana & Paullinia cupana & GU 1 & Warrenchem \\
\hline 41 & Guarana & Paullinia cupana & GU 2 & Warrenchem \\
\hline 42 & Horse chestnut & Aesculus hippocastanum & $\mathrm{HC}$ & Bioharmony \\
\hline 43 & Horsetail $\mathrm{Hb}$ & Equisetum arvense. & $\mathrm{HT}$ & Warrenchem \\
\hline 44 & African potato & Hypoxis hemerocallidea & $\mathrm{HH}$ & * \\
\hline 45 & Juniper & Juniperus sp. & $\mathrm{JU}$ & * \\
\hline 46 & Kava kava & Piper methysticum & KA 1 & Biomox \\
\hline 47 & Kava kava & Piper methysticum. & KA 2 & Chempure \\
\hline 48 & Kava kava & Piper methysticum & KA 3 & Warrenchem \\
\hline 49 & Kelp & Laminariae hyperborea & KE 1 & Warrenchem \\
\hline 50 & Kelp & Laminariae hyperborea & KE 2 & * \\
\hline 51 & Kelp & Laminariae hyperborea & KE 3 & * \\
\hline 52 & Licorice root & Glycyrrhiza glabra & $\mathrm{LI}$ & Warrenchem \\
\hline 53 & Millefolli & Achillea millefolium & MF & * \\
\hline 54 & Milkthirstle & Silybum marianum & MT 1 & Warrenchem \\
\hline 55 & Milkthirstle & Silybum marianum & MT 2 & Warrenchem \\
\hline 56 & Olive leaf extract & Oleae europaea & $\mathrm{OL}$ & Warrenchem \\
\hline 57 & Evening primrose & Oenothera bienns & OE & Bioharmony \\
\hline 58 & Passion flower & Passiflora & PF 1 & Bioharmony \\
\hline 59 & Passion flower & Passiflora & PF 2 & Warrenchem \\
\hline 60 & Parilla herb & Menispermum canadense & PR & * \\
\hline 61 & Pasque flower & Pulsatillae vulgaris & $\mathrm{PL}$ & * \\
\hline 62 & Cow's lip roots & Primulae vulgaris & $\mathrm{PI}$ & * \\
\hline 63 & Pusque flower & Anemone pulsatilla & $\mathrm{PU}$ & * \\
\hline 64 & Puma tablet & combined herbs & PM & * \\
\hline 65 & Butcher's broom & Ruscus aculeatus & RA & Bioharmony \\
\hline 66 & Rutin & isolated compound & $\mathrm{RU}$ & Chempure \\
\hline 67 & Saw palmetto & Serenoa serrata & $\mathrm{SP}$ & Bioharmony \\
\hline 68 & Senna leaf & Cassia angustifolia & $\mathrm{SN}$ & Warrenchem \\
\hline 69 & St John's wort & Hypericum perforatum & SJ 1 & Warrenchem \\
\hline 70 & St John's wort & Hypericum perforatum & SJ 2 & Chempure \\
\hline 71 & St John's wort & Hypericum perforatum & SJ 3 & Warrenchem \\
\hline 72 & St John's wort & Hypericum perforatum & SJ 4 & Bioharmony \\
\hline 73 & Taheebo & Tabebuia arellanedae & TB 1 & Bioharmony \\
\hline 74 & Taheebo & Tabebuia arellanedae & TB 2 & Warrenchem \\
\hline 75 & Bearberry & Uva ursi & UV & Warrenchem \\
\hline
\end{tabular}




\begin{tabular}{|l|l|l|l|l|}
\cline { 5 - 5 } 76 & Valerian & Valeriana officinalis & VR & Warrenchem \\
\hline 77 & Wheat fibre & Bran & WF & Lion heart \\
\hline 78 & Wild yam powder & Dioscorea villosa L. & WY & Warrenchem \\
\hline 79 & Wormwood & Artemisia afra & WW & Warrenchem \\
\hline 80 & Yarrow herba & Achillea millefolium L. & YW & Warrenchem \\
\hline 81 & Yorba & Ilex paraguartensis & YB & Warrenchem \\
\hline
\end{tabular}

* not specified

In evaluating the different spray reagents acetone leaf extracts of four Combretum species containing different chemical compounds (Eloff et al., 2008) and collected from the Lowveld National Botanical Garden. The species used were: C. apiculatum subsp apiculatum (1), C. imberbe (10), C. nelsonii (17) and C. woodii (21) (Eloff, 1999)

\section{Extraction.}

Five hundred $\mathrm{mg}$ of the dried powdered herbal material was extracted with $5 \mathrm{ml}$ acetone (Eloff, 1988) under vigorous shaking and the insoluble residue was removed by centrifugation at $1300 \mathrm{x} \mathrm{g}$ for 5 mins. The marc was re-extracted twice and the acetone was removed from the combined extracts under an air stream at room temperature. Samples $(1.0 \mathrm{~g})$ were also extracted under reflux at $60^{\circ} \mathrm{C}$ with $10 \mathrm{ml}$ methanol for 10 mins and the extract recovered by filtration as specified in the British Herbal Pharmacopoeia [Anonymous, 1996] [BHP]. Extracts with a concentration of $20 \mathrm{mg} / \mathrm{ml}$ were prepared in acetone for TLC.

\section{Thin layer chromatography}

TLC of the extracts with a concentration of $20 \mathrm{mg} / \mathrm{ml}[5 \mu$ l equivalent to c. $100 \mu \mathrm{g}$ of extract] was carried out on plastic or aluminiumbacked silica gel 60 F254 plates from Merck. Development to c. $9 \mathrm{~cm}$ took place in glass TLC chambers with freshly made up solvents allowed to equilibrate within the tank for 1-2 $\mathrm{h}$. The composition of the solvent systems finally used were benzene:ethanol:ammonia [9:1:0.1] [BEA], chloroform:ethylacetate:formic acid [5:4:1] [CEF] and ethylacetate:methanol:water [10:1.35:1] [EMW] (Kotze and Eloff, 2002).

\section{Observation of separation}

Plates were investigated under $254 \mathrm{~nm}$ UV light to note quenching of absorbance. Plates were also investigated under $350 \mathrm{~nm}$ to note fluorescence before, and in some cases also after spraying with the spraying reagent. Spraying reagents for visualizing components were also made up fresh. Chromatograms were carefully heated at $105^{\circ} \mathrm{C}$ until optimal colour development. The following spray reagents were used: $20 \%$ toluene-sulphonic acid in chloroform, $15 \%$ of $85 \%$ phosphoric acid in methanol, $0.5 \%$ vanillin in $80 \%$ ethanolic sulphuric acid, 20\% perchloric acid,5\% p-anisaldehyde in 5\% ethanolic sulphuric acid and 25\% trichloroacetic acid in chloroform (Stahl, 1969).

\section{Recording chromatograms}

Fluorescence under UV light was recorded with a digital camera (results not shown). A Hewlett Packard Scanjet 5100C scanner was used to scan in other chromatograms. Visualization was improved by changing contrast, intensity and/or brightness using picture editing software such as Microsoft Picture Editor.

\section{Results and discussion Extractant}

Five herbal medicines containing different classes of chemical compounds were selected to compare the extraction process. In this case the plant material was only extracted with acetone once. In all cases acetone extracted more compounds from the herbal medicine than the methods recommended in the BHP did [Table 2]. The procedure is also much easier and cheaper especially if a large number of samples are to be extracted. An additional benefit is that quantitative data can be obtained easily due to the volatility of the acetone so that it is possible to compare herbal material from different origins better and to know exactly how much material is used for each TLC analysis. 
Table 2 : The extraction of several herbal medicinal products with the method recommended in the British Herbal Pharmacopoeia [BHP] $[1 \mathrm{~g}$ powder $+10 \mathrm{ml}$ extractant] or with a single extraction by acetone $[0.5 \mathrm{~g}$ powder $+5 \mathrm{ml}$ acetone. shaken cold $]$.

\begin{tabular}{|c|c|c|c|}
\hline Plant & Extraction procedure according to the BHP & $\begin{array}{l}\% \text { dry weight extracted by } \\
\text { Acetone }\end{array}$ & $\begin{array}{l}\% \text { dry weight extracted by BHP } \\
\text { method }\end{array}$ \\
\hline Agnus castis & heat with $\mathrm{MeOH}$ on water bath and filter & 2.7 & 2.6 \\
\hline Milk Thistle & defat by reflux petroleum ether, extract hot $\mathrm{MeOH}$ & 12.8 & 0.9 \\
\hline Ginkgo leaves & extract with $\mathrm{MeOH}$ on water bath & 4.5 & 1.9 \\
\hline Hypericum & extract with $\mathrm{MeOH}$ on water bath & 3.1 & 1.5 \\
\hline Kava-Kava & extract under reflux with boiling $\mathrm{CHCl}_{3}$ & 2.8 & 1.8 \\
\hline
\end{tabular}

toluenesulphonic acid

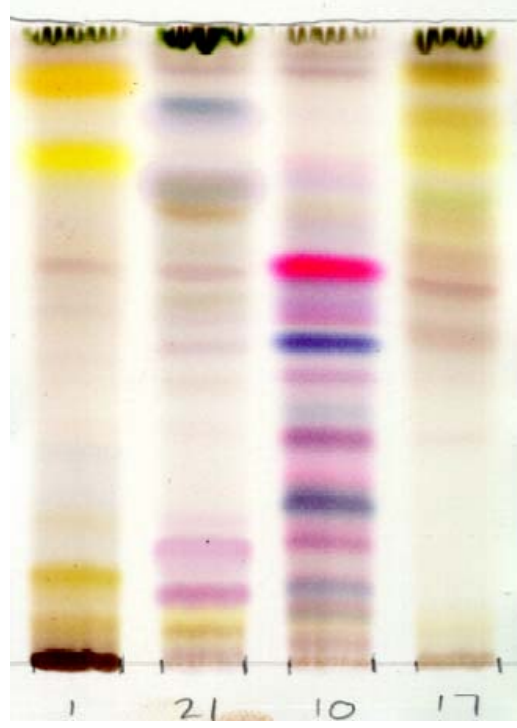

p-anisaldehyde

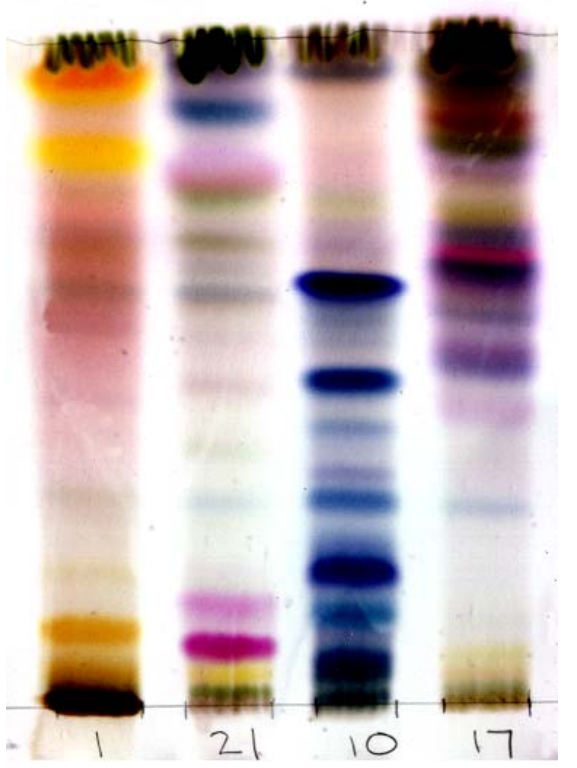

perchloric acid
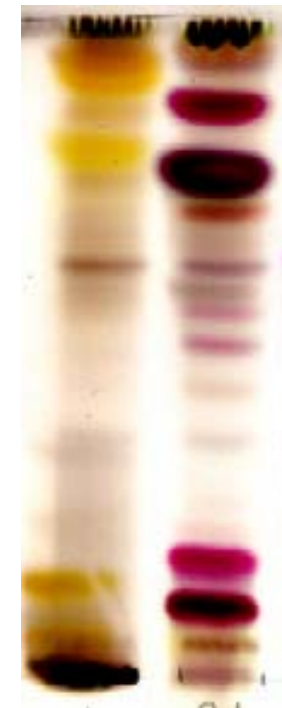

21

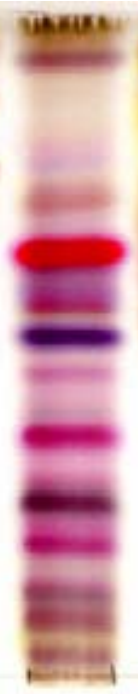

10

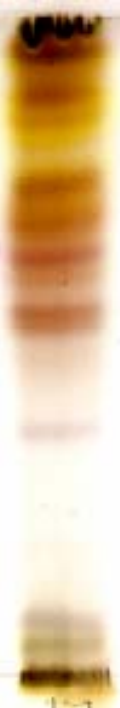

vanillin

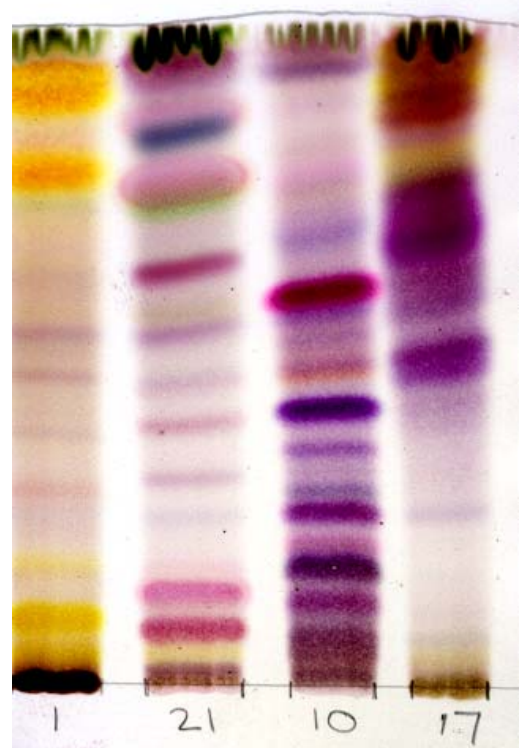

trichloroacetic acid

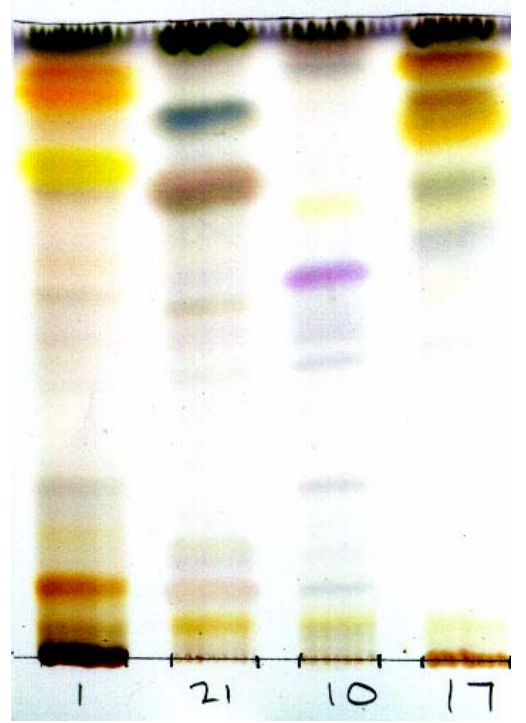

nhosnhoric acid

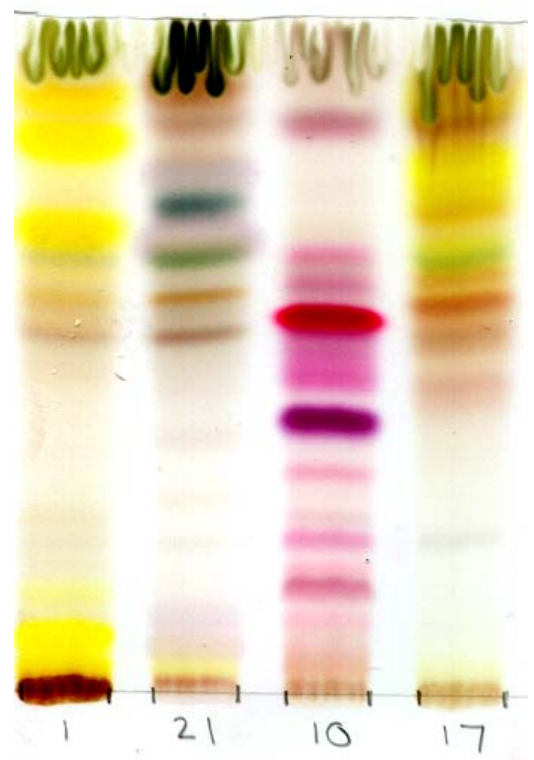

Figure 1: Comparison of several spray reagents used for visualizing chemical compounds present in $100 \mu \mathrm{g}$ acetone leaf extracts and separated with CEF Combretum apiculatum [1] , Combretum imberbe [10], Combretum nelsonii [17] and Combretum petrophilum [21]. 
To test whether similar compounds are extracted with acetone and the BHP extractants, extracts of the five species were chromatographed with BEA and sprayed with the vanillin spray reagent. More or less the same compounds were extracted with the different extraction techniques (results not shown).

\section{The efficiency of extraction}

Up to this stage we extracted samples in centrifuge tubes on a Vortex mixer. This is tedious as one sample has to be handled at a time. We compared extracting the finely powdered material using the Vortex mixer with extraction using an orbital shaker containing a test tube rack for the centrifuge tubes. There were hardly any differences in the results obtained with the two procedures [Table 3].

In most cases the first extraction removed close to $80 \%$ and two extractions removed c $90-95 \%$ of material extracted after three repetitions. . We later found that with a very fine powder equilibrium was established within one minute on the shaking machine.

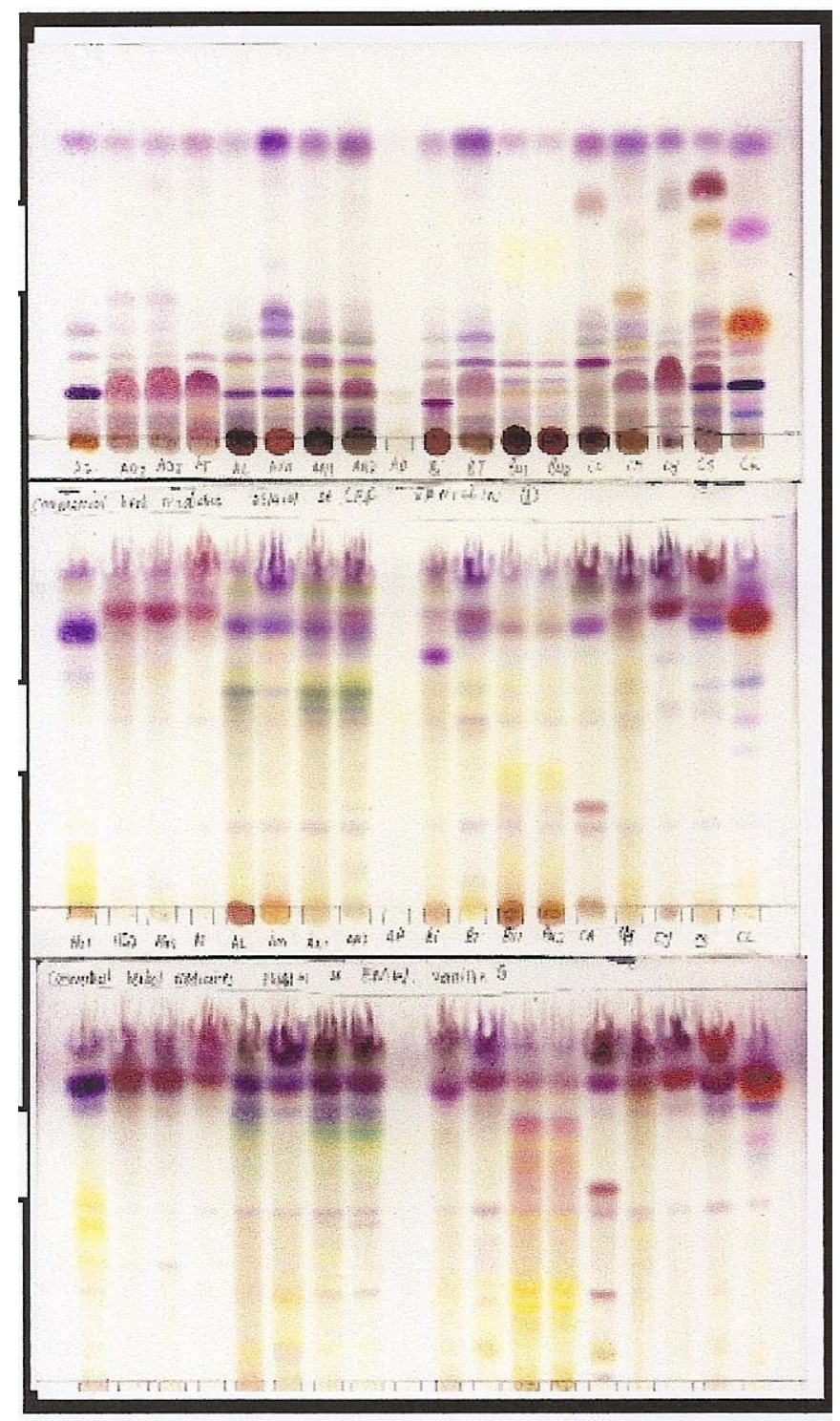

Figure 2a: Chromatograms of different products separated with CEF, BEA and EMW from top to bottom and sprayed with vanillinsulphuric acid. Different lanes from left to right $100 \mu \mathrm{g}$ of acetone extracts of AG1, AG2, AG3 -Agni castus, AT-Althea roots, AL- Alchemillae herb, AM-Amara tablet, AN1, AN2- Anserinae herba, AP-Apple cidar,BI- Biolite capsules, BT- Bitterorange, BU1, BU2-Buckthorn, CH-Chamomile, CY- Cayenna powder, CS-Chaste tree berry , CL-Clove 


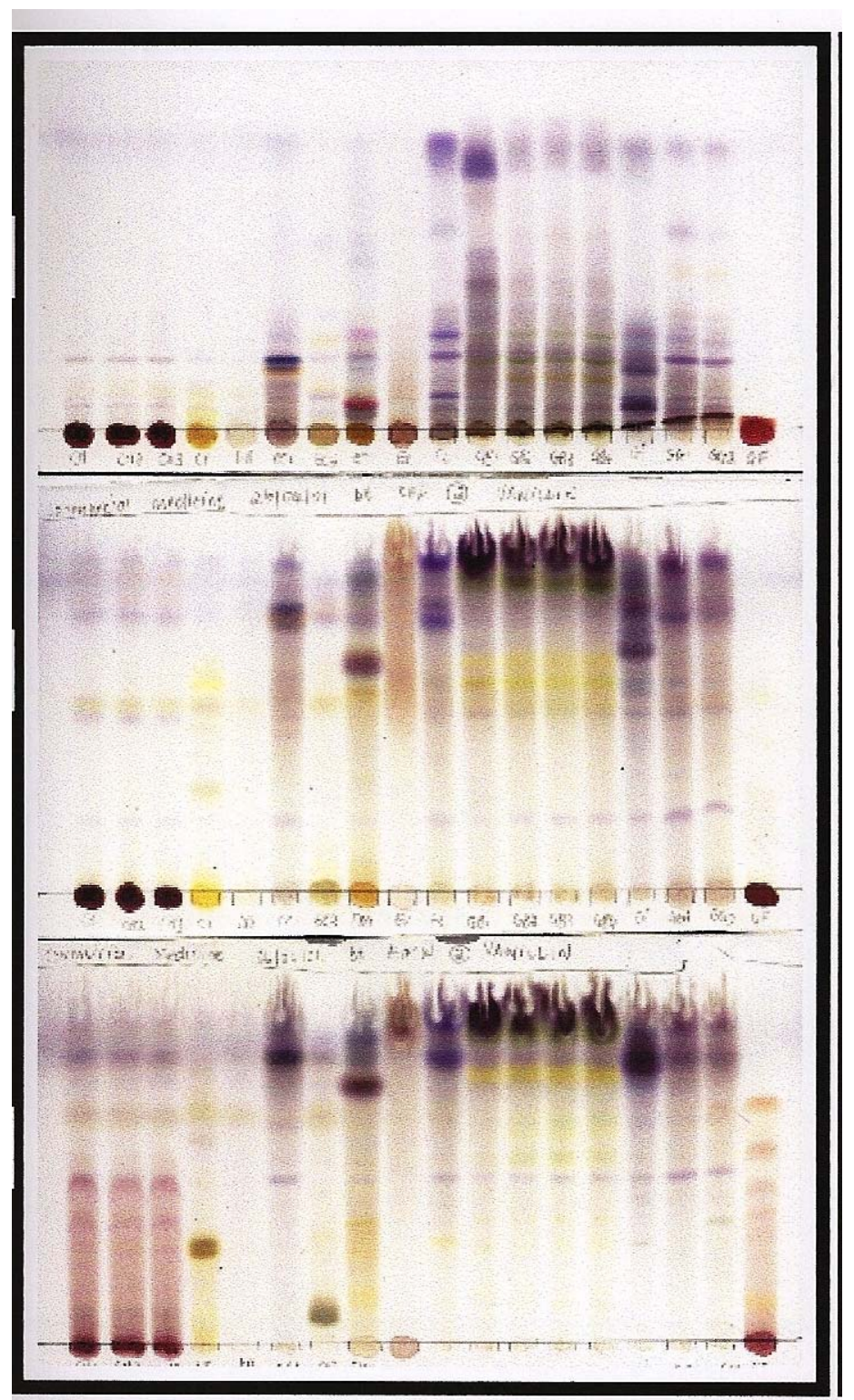

Figure 2b: Chromatograms of different products separated with CEF, BEA and EMW from top to bottom and sprayed with vanillinsulphuric acid. Different lanes from left to right $100 \mu \mathrm{g}$ of acetone extracts of CN1, CN2, CN3- Cinnamon, CT- Citrus extract, DA- Dandelion root, EC1, EC2- Echinaceae, EM-Emotone, EV-Evening primrose, Fl- Flores auranti, GB1, GB2, GB3, GB4Ginkgo biloba, GI- Ginger root, GG1, GG2- Ginseng, GF- Grape fruit seed

\section{Which spray reagent should be used?}

Forty four spray reagents were used for visualizing chromatograms of medicinal plants by Wagner and Bladt (1997) and in the BHP. We have been doing work on the chemistry and antibacterial activity of Combretaceae species in our laboratory [Eloff 1999]. Combretum species contain many triterpenoids, flavonoids and glycosides (Carr and Rogers, 1987). We selected four Combretum species containing different chemicals (Eloff et al., 2008) and tested a number of general TLC spray reagents on acetone extracts of these plants on different types of TLC plates using CEF, the same solvent system as Carr and Rogers (1987).

There were few differences between plastic and aluminium coated TLC plates. The aluminium covered plates tended to be destroyed by harsh chemicals and the plastic backed plates were deformed by heating for long periods. There were large differences using the different spray reagents (Figure 2), but in general using vanillin-sulphuric acid (0.1g vanillin in $28 \mathrm{ml}$ methanol:1 ml sulphuric acid) on aluminium backed plates gave good results and this was selected as standard treatment. 


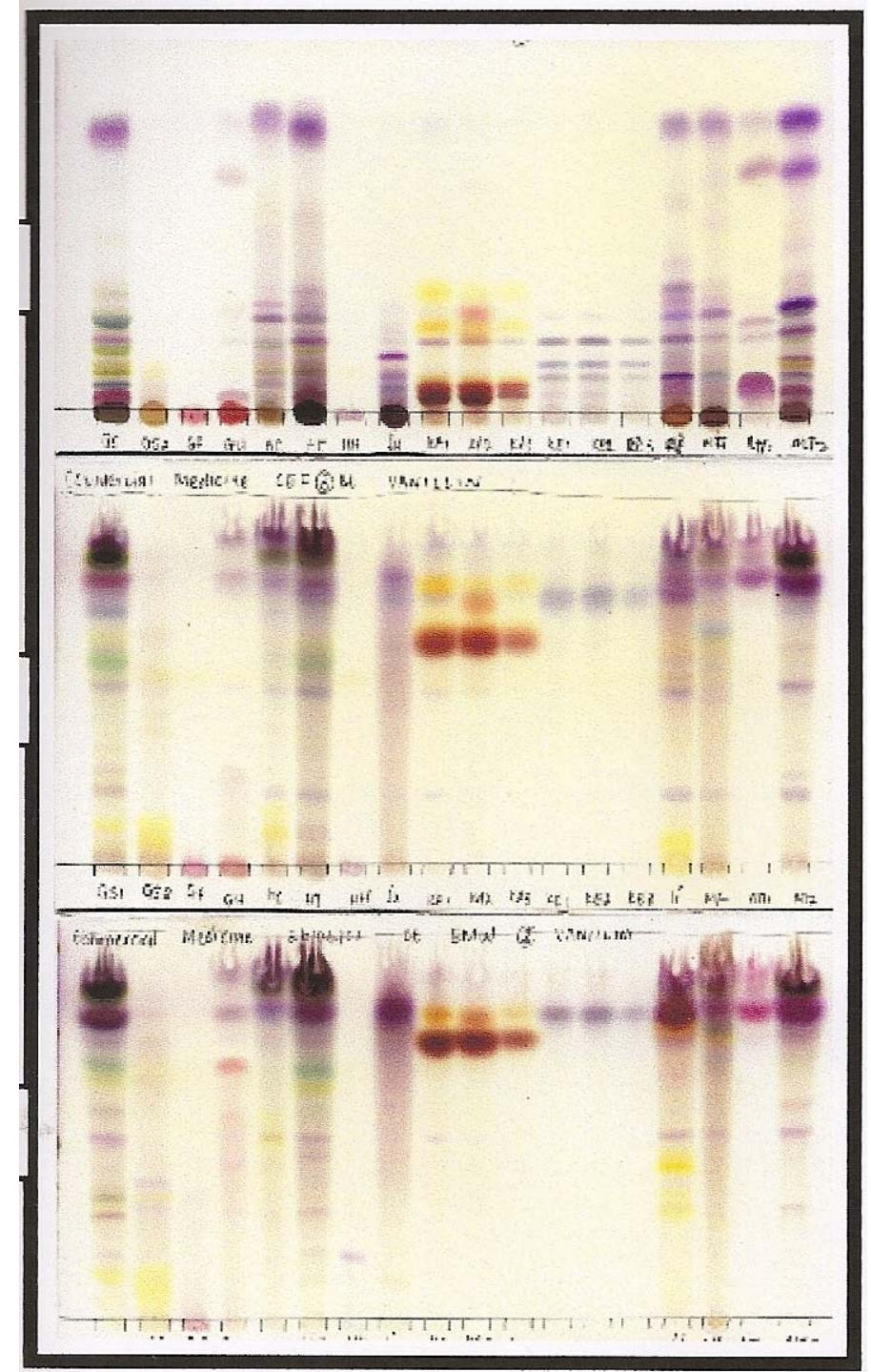

Figure 2c: Chromatograms of different products separated with CEF, BEA and EMW from top to bottom and sprayed with vanillinsulphuric acid. Different lanes from left to right $100 \mu \mathrm{g}$ of acetone extracts of GS1, GS2-Goldenseal, GP-Grape skin extract, GU1, GU2-Guarana, HC- Horse chestnut, HT-Horsetail herb, JU-Juniper, KA1, KA2, KA3-Kava Kava, KE1, KE2, KE3- Kelp, LILicorice root, MF- Millefolli, MT1, MT2- Milkthistle

Table 3: Quantity extracted in mg from $500 \mathrm{mg}$ of Agnus castus [A], Milk thistle seed [M], Ginkgo leaves [G], Hyperacid $\mathrm{Hb}[\mathrm{H}]$, Kava-Kava $[\mathrm{K}]$ by acetone using a Vortex shaker for 5 min $[\mathrm{V}]$, or an orbital shaking machine for $5 \mathrm{~min}$ [S]. [500 mg plant material $+5 \mathrm{ml}$ acetone].

\begin{tabular}{|l|l|l|l|l|l|l|l|l|l|l|}
\hline Sample & AV & AS & MV & MS & GV & GS & HV & HS & KV & KS \\
\hline $1^{\text {st }}$ extract & 24 & 23 & 122 & 121 & 35 & 37 & 28 & 27 & 21 & 21 \\
\hline $2^{\text {nd }}$ extract & 4 & 4 & 20 & 16 & 8 & 9 & 8 & 7 & 8 & 8 \\
\hline $3^{\text {rd }}$ extract & 2 & 2 & 6 & 8 & 3 & 2 & 5 & 4 & 2 & 2 \\
\hline total & 30 & 29 & 148 & 145 & 46 & 48 & 41 & 38 & 31 & 31 \\
\hline
\end{tabular}




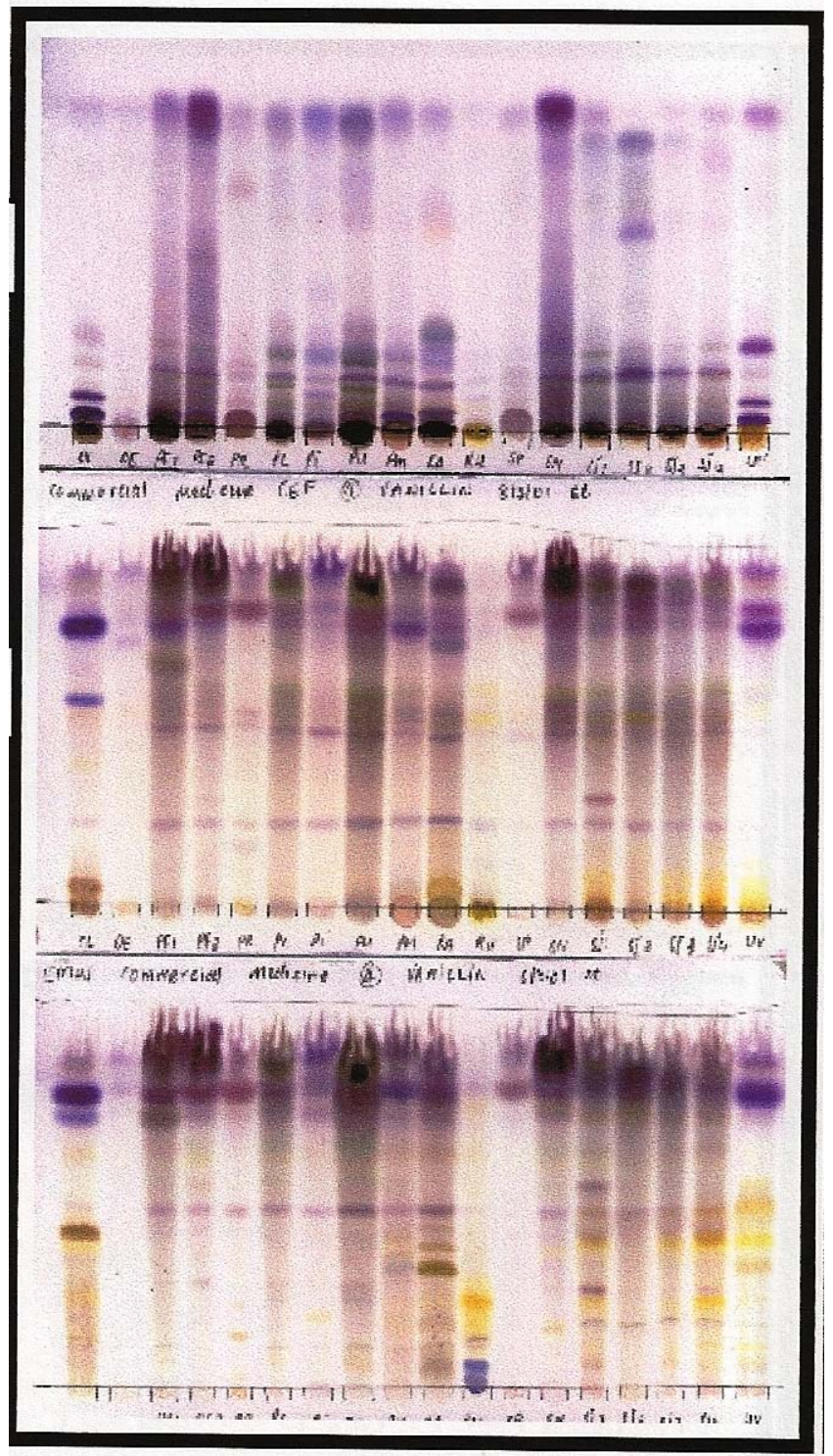

Figure 2d: Chromatograms of different products separated with CEF, BEA and EMW from top to bottom and sprayed with vanillinsulphuric acid. Different lanes from left to right $100 \mu \mathrm{g}$ of acetone extracts of OL-Olive leaf, OE-Oenothera bienns, PF1, PF2Passion flower, PR-Parilla herb ,PL-Pulsatillae vulgaris ,PI-Primulae vulg, PU-Pulsatilla, PM-Puma tablet, RA-Ruscus aculeatus, RU- Rutin, SN- Senna leaf, SP- Saw palmetto, SJ1, SJ2, SJ3, SJ4- St John's wort, UV-Uva ursi

\section{Which TLC solvent system should be used?}

We tested several existing solvent systems and decided on benzene:ethanol:ammonia [9:1:0.1] (BEA) which is an alkaline system excellent for non-polar compounds, chloroform:ethylacetate:formic acid [5:4:1] (CEF) which is acidic and good for intermediate polarity compounds and ethylacetate:methanol:water [10:1.35:1] (EMW)which is best for polar compounds (Kotze and Eloff, 2002). With these three systems compounds with a very wide range of polarities may be separated. In addition to the polarity differences the fact that one system is basic, one neutral and one acidic also helps in separating different compounds in the extracts.

As an example of the separation obtained, chromatograms developed with CEF, BEA and EMW and sprayed with Vanillinsulphuric acid for the different herbal medicines examined is presented in Figures 2a-e. When these chromatograms were investigated in $236 \mathrm{~nm}$ UV light and photographed with a digital camera before spraying many significant differences were observed [results not shown]. Observation of fluorescence under $236 \mathrm{~nm}$ of different chromatograms is frequently sufficient to ensure that the identity in the batch is the same as the claim on the label. In some cases overheating the chromatograms (Fig. 2e) spoiled the quality of the chromatograms, but difference could still clearly be seen.

With experience and using a volatile solvent such as acetone to prepare the extract to be chromatographed and careful heating of the plate it is possible to get chromatograms that are as good as those obtained with expensive, time consuming commercial apparatus (Figure 3). 


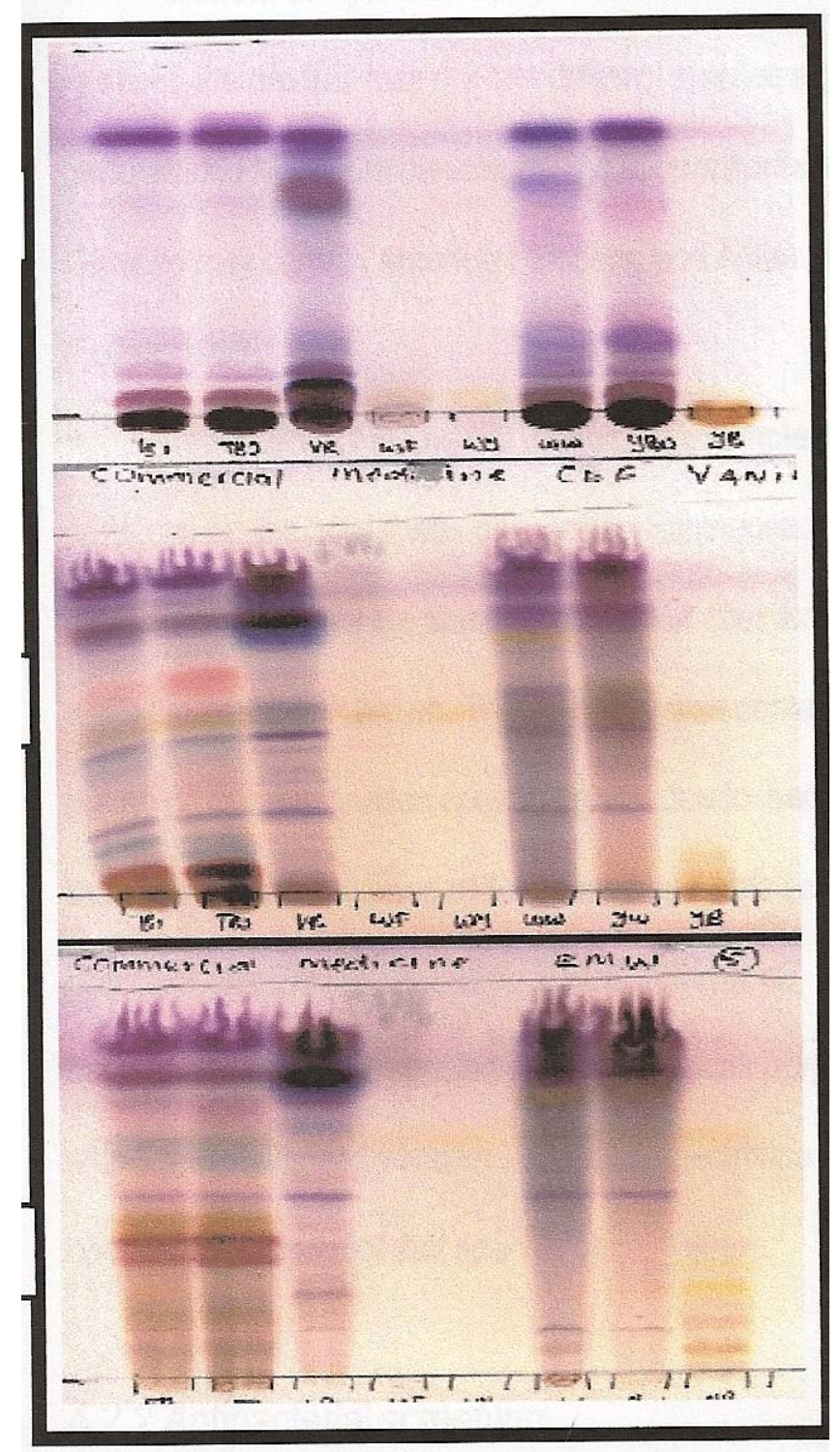

Figure 2e: Chromatograms of different products separated with CEF, BEA and EMW from top to bottom and sprayed with vanillinsulphuric acid. Different lanes from left to right $100 \mu \mathrm{g}$ of acetone extracts of TB1, TB2- Taheebo, VR-Valerian, WF-W heat fibre, WW- Wormwood, YW- Yarrow herba, YB- Yorba

\section{How efficient is the process to identify different herbal medicines}

Even with only one of the three solvent systems described most of the herbal medicines could already be distinguished from each other. It was satisfying that analyzing the same product from different origins with the Anserinae, Buckthorn, Cinnamon, Ginkgo, Ginseng, Kelp and Taheebo extracts led to virtually identical chromatograms. In some cases there were some differences, but in general the chromatograms were similar enough to identify the species from different origins with the extracts from Ginseng, Kava Kava, Passion Flower and St John's Wort.

The value of this approach is probably best demonstrated by the cases where major differences were present with different extracts from samples labelled Agnus casti, Echinaceae, Guarana and Milk Thistle. This may be due to a mistake made somewhere along the line or to a different part of the plant used. Because the CEF solvent system separated many compounds of intermediate polarity, this system was even more useful than the BEA system on its own. By using all three systems and therefore covering a very wide range of polarities any ambiguity could be eliminated.

It should be understood that it is hardly feasible to identify a plant species with $100 \%$ certainty by just investigating the chemical profile. Two different species of Cinnamomum gave essentially identical chromatograms (Fig $2 \mathrm{~b}$ ). On the other hand two closely related Leonotus species considered to be the same species by taxonomists had major differences in chemical composition based on TLC of extracts (Eloff, 2010). In some cases even experienced taxonomists can only identify species if fertile material is available.

In our experience it is important to quantify the mass separated by TLC. If the quantity is too low some compounds will not be visible and if the quantity is too high streaking will limit the separation. Chromatographing $100 \mu \mathrm{g}$ of the extract usually led to good chromatograms. It should be stressed that TLC only provides quantitative data under well defined conditions. By separating the same 
quantity from different samples under similar conditions or co-chromatography with standards some quantitative conclusions can be made.

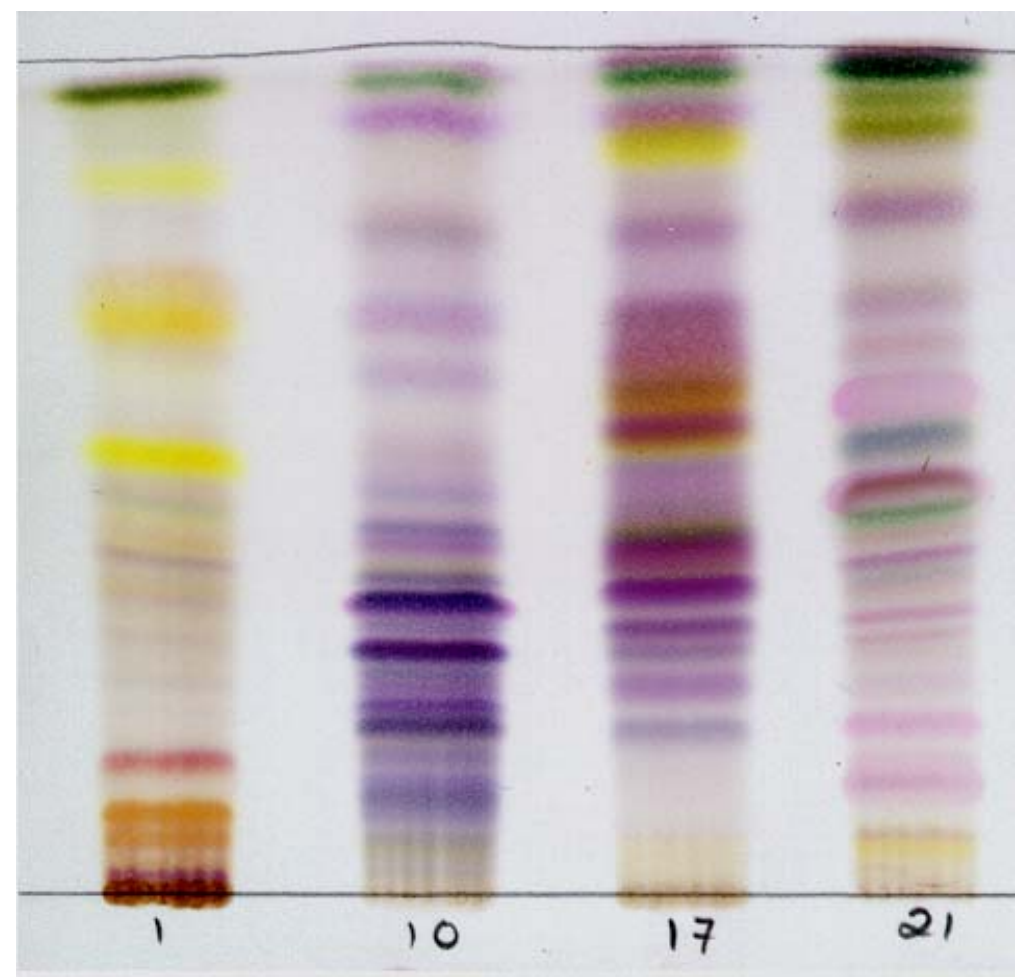

Figure 3: Chromatograms of 100 ug of acetone leaf extracts of Combretum apiculatum [1] , Combretum imberbe [10], Combretum nelsonii [17] and Combretum petrophilum [21] separated using the BEA solvent system. This indicates the quality of fractionation that can be attained with experience using low technology and doing chromatography under well saturated conditions.

\section{Conclusions}

The BEA and CEF chromatograms indicate that with even one solvent system and detection system, separation of extracts of most of the herbal medicines by TLC already give unique patterns. By using the different solvent systems and spray reagents any uncertainty should be resolved. The proposed system is very simple and many analyses can be performed per day without the requirement for sophisticated apparatus. It remains to be seen how wide the difference between different populations of the same species is. By co-chromatography of standards occurring in most plants such as $\beta$-sitosterol, rutin or a standard known to occur in the plant investigated, the identification can be more definite. The provision of voucher material for co-analysis with samples supplied by collectors or growers, chromatograms available on a website or chromatograms accompanying material supplied by large scale suppliers could be a practical use of the results obtained in this study. This method has found application in the quality control of the most important African medicinal plants in the recently published African Herbal Pharmacopoeia produced by the Association for African Medicinal Plant Standards (AAMPS) (Brendler, et al., 2010).

\section{Acknowledgement}

The research was funded by Biomox Pharmaceuticals, THRIP and the National Research Foundation.

\section{References}

1. Anonymous, (1996). British Herbal Pharmacopoeia. British herbal medicine Association, Guildfort, Great Britain

2. Blumenthal M, Busse W R, Goldberg A, Gruenwald J, Hall T, Riggens C W and Rister R S eds; Klein S and Rister R S translators (1998) The complete German commission E monographs: Therapeutic guide to herbal medicines. American Botanical Council, Austin TX USA

3. $\quad$ Brendler T, Eloff JN, Gurib-Fakim A, Phillips D (Eds) (2010). African Herbal Pharmacopoeia. AAMPS publishing, Mauritius ISBN 9789990389098, 289 pp. 
4. Carr J.D. and Rogers, C.B. (1987) Chemosystematic studies of the genus Combretum [Combretaceae], I. A convenient method of identifying species of this genus by a comparison of the polar constituents extracted from leaf material. South African Journal of Botany 53, 173-176.

5. Eloff J N (1998). Which extractant should be used for the screening and isolation of antimicrobial components from plants? J. Ethnopharmacology, 60, 1-8.

6. Eloff J N (1999). The antibacterial activity of 27 southern African members of the Combretaceae. S. Afr. J. Sci. 95, 148-152.

7. Eloff JN (2010). Die groot verskil in chemiese samestelling en antibakteriese aktiwiteit van twee na-verwante Leonotis spesies (Lamiaceaea) mag taksonomiese waarde hê. Suid-Afrikaanse Tydskrif vir Natuurwetenskap en Tegnologie 29, 30-38.

8. Eloff JN, Katerere DR, McGaw LJ (2008). The biological activity and chemistry of the southern African Combretaceae. J. Ethnopharmacology 119, 686-699.

9. Groenewegen W A and Heptinstall S (1986). Feverfew. Lancet 1986, 44-45

10. Kotze M and Eloff J N (2002). Extraction of antibacterial compounds from Combretum microphyllum (Combretaceae). South Afr. J. Botany $68,62-67$.

11. Liberty LE and der Marderosian A (1978). Evaluation of commercial Ginseng products. J Pharmaceutical Sci. 67, 1487-1489.

12. McCaleb R (2000). Agribusiness in Sustainable Natural African Plant Products [ASNAPP] Roundtable Conference. Cape Town, South Africa

13. Robbers J E and Tyler V E (1999). Tyler's Herbs of Choice: The Therapeutic use of Phytomedicinals. Haworth Herbal Press, London

14. Stahl E. (Ed.) [1969] Thin layer chromatography. A laboratory handbook. Springer-Verlag, Berlin, $1041 \mathrm{pp}$.

15. Van Wyk B-E and Wink M (2004). Medicinal Plants of the World. Timber Press, $480 \mathrm{pp}$.

16. Wagner H and Bladt, S. (1996). Plant Drug Analysis A Thin layer Chromatography Atlas 2nd Ed, Springer-Verlag BerlinWagner $\mathrm{H}$ and Bladt, S. (1996]).Plant Drug Analysis A Thin layer Chromatography Atlas 2nd Ed, Springer-Verlag Berlin, 384 pp. 